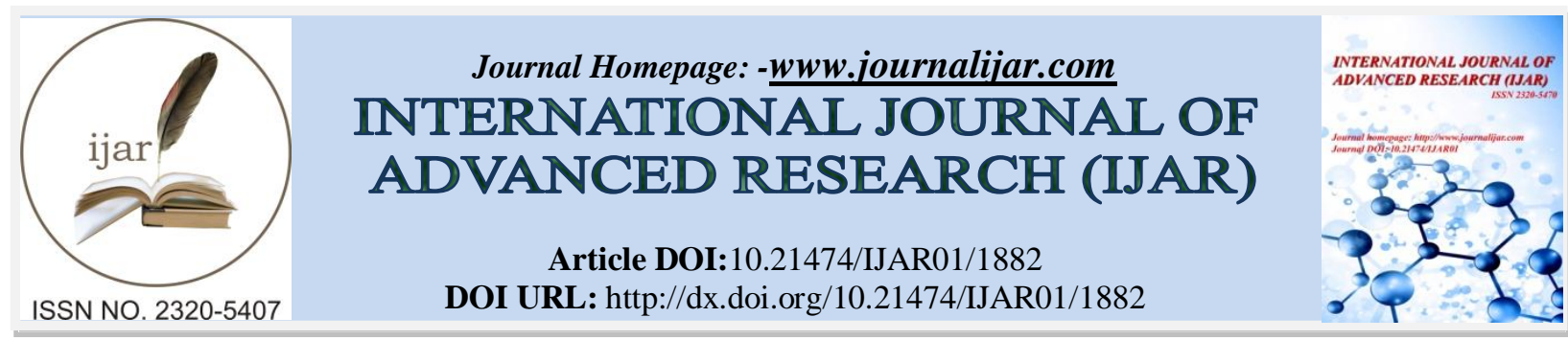

RESEARCH ARTICLE

\title{
EXPERIMENTAL DESIGN USE FOR ETHANOLIC TRANSESTERIFICATION OPTIMIZATION FOR BIODIESEL PRODUCTION CATALYZED BY FICUSTRICHOPODA LATEX LIPASE.
}

\section{Mouaimine Mazou ${ }^{1}$, Andriano J. Djossou ${ }^{1}$, Fidele Paul Tchobo ${ }^{1}$, Pierre Villeneuve ${ }^{2}$ and Mohamed M. Soumanou ${ }^{1}$.}

1. Unite de Recherche en Génie Enzymatique et Alimentaire, Laboratoire d'Etude et de Recherche en Chimie Appliquée, Ecole Polytechnique d'Abomey-Calavi, Université d'Abomey-calavi, 01 BP 2009, Cotonou, Bénin.

2. CIRAD, UMR Ingénierie des Agro-polymères et Technologies Emergentes, Campus Supagro/INRA, Montpellier, France.

\section{Manuscript Info}

Manuscript History

Received: 12 August 2016

Final Accepted: 16 September 2016

Published: October 2016

Key words:-

Latex; Ficustrichopoda;

Transesterification reaction;

Experimental design.

\section{Abstract}

This work focused on optimization of biodiesel production from vegetal oil catalyzed by Ficustrichopoda latex using a response surface analysis. Ethanol substrate molar ratio, enzyme amount (latex), water activity, reaction duration, agitation speed and reaction temperature were examined. After use a box-Behnken design, the Plackett-Murman design were use as screening test to sort the factors while emphasizing most influential. The function of desirability shows that the value of the coefficient of maximum yield of $\mathrm{EE}$ estimated by the model $(45,96 \%)$ corresponds to the values of the levels according to: aw $=0,63$; latex rate $=24,85 \%$; reaction duration 7 days and molar ratio TG:Eth (1:5). It appears that the recycling of latexes of $F$. trichopoda as biocatalyst after two cycle catalytic of transesterification is not for the moment possible.

Copy Right, IJAR, 2016,. All rights reserved.

\section{Introduction:-}

Biodiesel (fatty acid methyl esters or fatty acid ethyl esters) is a processed fuel mainly derived from vegetable oils, animal fats and waste oil. Among the possible candidates for an alternative energy source, biodiesel has attracted much attention because its physical and chemical properties and energy content are similar to those of petroleum diesel (Robles-Medina et al., 2009). Currently, biodiesel is produced from vegetable oils in Europe and North America, and from waste edible oil in Japan and China (Wang et al., 2007).

Conventional biodiesel production methods involve the use of acid or base chemical catalysts via homogenous or heterogeneous processes (Brunschwig et al., 2011). Downstream processing costs and environmental problems associated with biodiesel production and byproducts recovery have investigated many research teams to develop new alternative catalysis processes to replace the homogenous catalysis processes generally used in industries (Akoh et al., 2007). In contrast, enzymes (lipases) allow the production of specific alkyl esters, easy recovery of the glycerol, and transesterification of TG with high free fatty acid content (Soumanou et al., 2012). It is now known that lipases contained in latex in some plants have catalytic properties and numerous industrial applications (Mazou et al., 2016). For instance, papaya (Carica papaya) latex has already been described in the modification of fats and oils (Villeneuve 2003), in esterification and transesterification reactions (Caro et al., 2000), and more recently in the resolution of racemic mixtures (Cheng \& Tsai 2004). 
Moreover, the African vegetable biomass is of growing interest for the research and industrial communities owing to the significant number and variety of bioactive components it contains (Villeneuve 2003). Among them, the identification and the characterization of plant lipases were little reported and therefore, could show an interest in the context of bioconversion of greasy substances like fats and oils.

In this study, a response surface analysis for biodiesel production from vegetal oil with Ficustrichopoda latex lipase was investigated. Ethanol substrate molar ratio, enzyme amount (latex), water activity, reaction duration, agitation speed and reaction temperature were examined.

\section{Material and Methods:-}

\section{Materials:-}

The latexes of Ficustrichopoda were sampled in Benin Republic, in the North-West, in the department of Donga, at the foot of the mountains of Tanéka-koko (commune of Copargo).

Fresh latex was collected after incision of their trunk. The exuded latex was allowed to run down and drip into collecting devices.

The collected latex was spread on trays and left for drying in air at $40^{\circ} \mathrm{C}$ for $14 \mathrm{~h}$. All trays and other materials used in the latex collection and drying were washed thoroughly with water and detergent soap and kept dried.

The dried products were packed in air-tight plastic containers and stored in a cool, dry place. Plastic containers of $100 \mathrm{~g}$ capacity were used to pack dried latex since metal containers would result in a loss of enzyme activity (Jeana et al., 2013). These were kept and stored in a freezer at $-20^{\circ} \mathrm{C}$ (Nitsawang et al., 2006) in order to avoid reduction of its shelf life. In fact, it is generally accepted that a month's stability of an enzyme at $45^{\circ} \mathrm{C}$ is roughly equal to that of one year at room temperature (Jeana et al., 2013).

All the chemicals, solvents and alcohols used were of analytical grade and purchased from Sigma, St Louis, MO, USA. The high performance silica plates (HPTLC plates, $20 \times 10 \mathrm{~cm}$ Silica-gel 60 F254) for thin-layer chromatography (TLC) were purchased from Merck (Darmstadt, Germany). The vegetable oil used (palm oil) was of food quality and was purchased in a local supermarket in Benin.

\section{Apparatus and experimental procedure:-}

The transesterification reactions were carried out in shaking flasks and heated to the reaction temperature on a reciprocal shaker. A sample of $100 \mu \mathrm{L}$ was taken centrifuged to obtain the upper layer for gas chromatographic analysis.

\section{Experimental design:-}

A box-Behnken design was employed to study the response $\mathrm{Y}$, namely ethyl conversion. The independent variables were X1, X2, X3, X4, X5and X6, representing ethanol substrate molar ratio, enzyme amount (latex), water activity, reaction duration, agitation speed and reaction temperature, respectively. The settings for each independent variable were as follows (low/ high value), (Table 1)

Table 1:- Independent variables and their levels for central composite design.

\begin{tabular}{|l|l|l|l|l|}
\hline \multicolumn{2}{|l|}{} & Variable level \\
\hline Independent variable & Code & Unité & Niveau -1 & Niveau +1 \\
\hline Molar ratio (TAG : Eth) & X1 & $/$ & $(1: 5)$ & $(5: 1)$ \\
\hline Enzyme amount (latex) & X2 & $\%$ & 0 & 20 \\
\hline Aw & X3 & $/$ & 0,05 & 0,964 \\
\hline Reaction duration & X4 & day & 1 & 7 \\
\hline Agitation speed & X5 & tpm & 50 & 300 \\
\hline Reaction temperature & X5 & ${ }^{\circ}$ C & 30 & 60 \\
\hline
\end{tabular}

After using a box-Behnken design we decided to initially use a screening plan. It is a plan of first degree making it possible to sort the factors while emphasizing most influential. It is also useful to evaluate the relevance of a model of first degree. We chose the plan of Plackett-Murman because it is generally more employed in the studies similar to our because of its economy in term of the number of tests. 


\section{Estimation of fatty acid methyl ester:-}

The fatty acid ethyl ester content in the reaction mixture was analyzed on GC-14B gas chromatograph equipped with FFAP capillary column $(0.32 \mathrm{~mm} \times 25 \mathrm{~m})$ and FID detector. The column temperature was kept at $150^{\circ} \mathrm{C}$ for 0.5 min, raised to $250^{\circ} \mathrm{C}$ at $15^{\circ} \mathrm{C} / \mathrm{min}$ and maintained at this temperature for $10 \mathrm{~min}$. The temperatures of the injector and detector were set at 245 and $250^{\circ} \mathrm{C}$, respectively. Nitrogen at $70 \mathrm{ml} / \mathrm{min}$ was used as the carrier gas. Pentadecanoic acid (C15:0, Sigma) ethyl ester at $2 \mathrm{mg} / \mathrm{ml}$ was used as the internal standard. The conversion of biodiesel was calculated as the percentage by weight of fatty acid methyl esters formed divided by the weight of feed stock initially taken for the reaction.

\section{Result and Discussion:- \\ RSM model fitting:-}

The major objective of this study was the development and evaluation of a statistical approach to optimize the lipase-catalyzed process.

\section{Construction of the plan of sifting and realization of the tests:-}

\section{Experiments matrix:-}

The plan of Plackett-Murman for 6 factors, includes 12 tests. It was carried out using Minitab software, version 14. The Ethyl Ester formation was determined (Table 2).

Table 2:- Matrix of screening plan and response

\begin{tabular}{|l|l|l|l|l|l|l|l|}
\hline $\mathrm{N}^{\circ}$ & aw & $\begin{array}{l}\text { Reaction } \\
\text { duration }\end{array}$ & Molar ratio & $\begin{array}{l}\text { Enzyme } \\
\text { amount } \\
\text { (latex) }\end{array}$ & $\begin{array}{l}\text { Reaction } \\
\text { temperature }\end{array}$ & Agitation speed & $\begin{array}{l}\text { EE } \\
(\%)\end{array}$ \\
\hline 1 & 0.05 & 1 & $(5: 1)$ & 20 & 60 & 50 & 6.716 \\
\hline 2 & 0.964 & 1 & $(5: 1)$ & 0 & 30 & 50 & 0.000 \\
\hline 3 & 0.964 & 5 & $(1: 5)$ & 20 & 60 & 50 & 20.428 \\
\hline 4 & 0.964 & 5 & $(1: 5)$ & 20 & 30 & 50 & 18.711 \\
\hline 5 & 0.05 & 5 & $(5: 1)$ & 20 & 30 & 300 & 13.972 \\
\hline 6 & 0.964 & 1 & $(1: 5)$ & 0 & 60 & 300 & 0.000 \\
\hline 7 & 0.05 & 1 & $(1: 5)$ & 0 & 30 & 50 & 0.000 \\
\hline 8 & 0.05 & 1 & $(1: 5)$ & 20 & 60 & 300 & 0.000 \\
\hline 9 & 0.964 & 1 & $(5: 1)$ & 20 & 30 & 300 & 14.095 \\
\hline 10 & 0.964 & 5 & $(5: 1)$ & 0 & 60 & 300 & 0.000 \\
\hline 11 & 0.05 & 5 & $(5: 1)$ & 0 & 60 & 50 & 0.000 \\
\hline 12 & 0.05 & 5 & $(1: 5)$ & 0 & 30 & 300 & 0.000 \\
\hline
\end{tabular}

The data processing was carried out by multiple linear regression using the Minitab software. The values of the effects and the regression coefficients of the model are given in table 3 .

Tableau 3:- Effects of estimated coefficient for the response.

\begin{tabular}{|l|l|l|l|}
\hline Term & Effete & Coefficient & $\begin{array}{l}\text { Probability } \\
(\mathrm{P}<\alpha=0.05)\end{array}$ \\
\hline Constant & & 5.910 & 0.001 \\
\hline Aw & 5.924 & 2.962 & 0.025 \\
\hline Reaction duration & 4.883 & 2.442 & 0.048 \\
\hline Molar ratio & -1.226 & -0.613 & 0.542 \\
\hline Enzyme amount (latex) & 11.820 & 5.910 & 0.001 \\
\hline Reaction temperature & -2.772 & -1.386 & 0.200 \\
\hline Agitation speed & -3.465 & -1.732 & 0.124 \\
\hline
\end{tabular}

These results which can also be represent by the diagram of Pareto (figure 1), show that molar ratio temperature agitation speed do not have of significant influence on the response to the selected degree of confidence $(\alpha=0,05)$ in the field of initial study plan. 


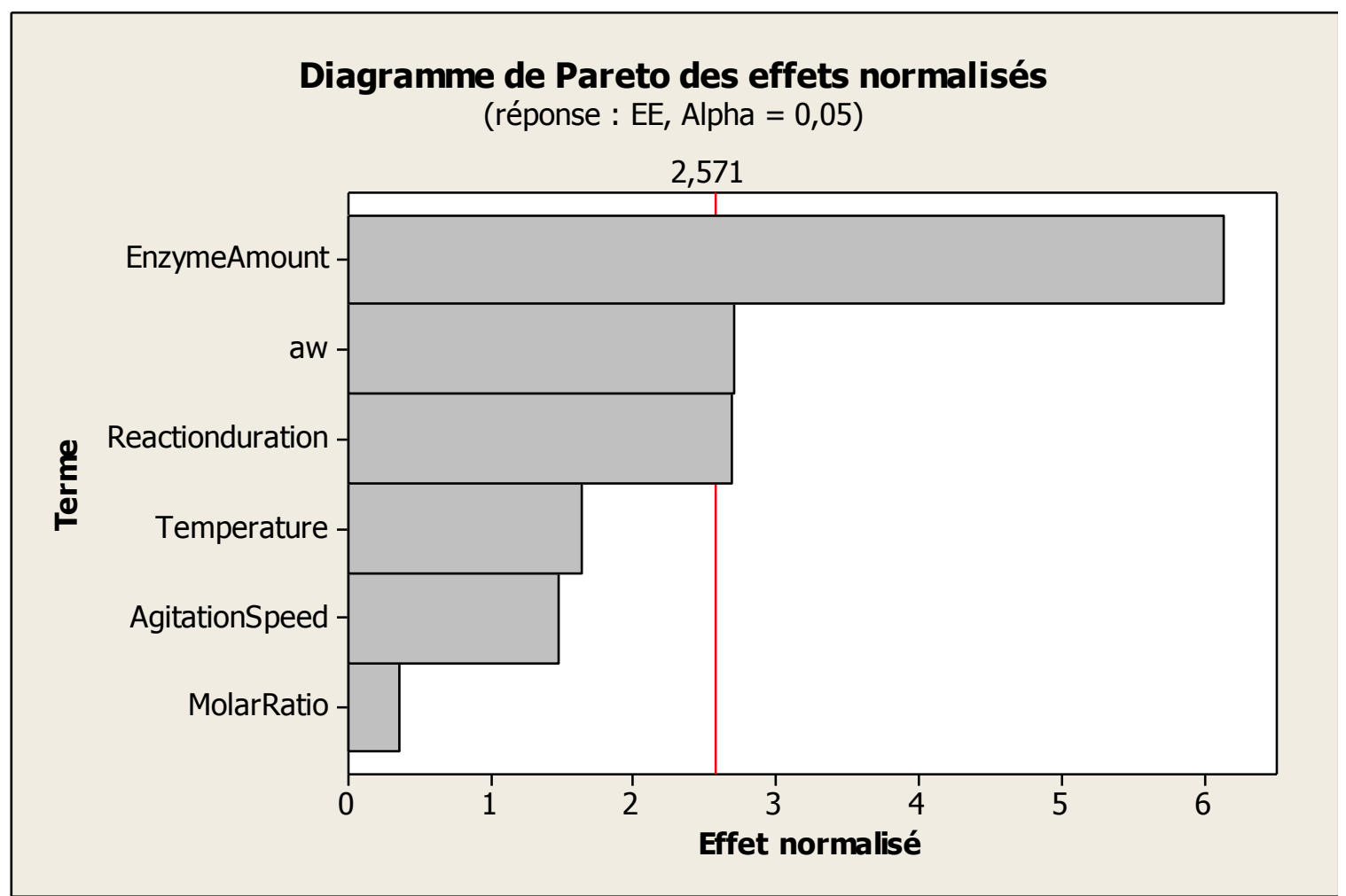

Figure 1:- Diagram of Pareto of the standardized effects.

In addition, the examination of the diagram of the answers estimated according to the measured answers (figure 2) shows that in spite of a good coefficient of regression $\left(R^{2}=0,9196\right)$ several points deviate from bisector. Indeed, the model of the first degree cannot account for the results of measurement in spite of the good $\mathrm{R}^{2}$ apparent.

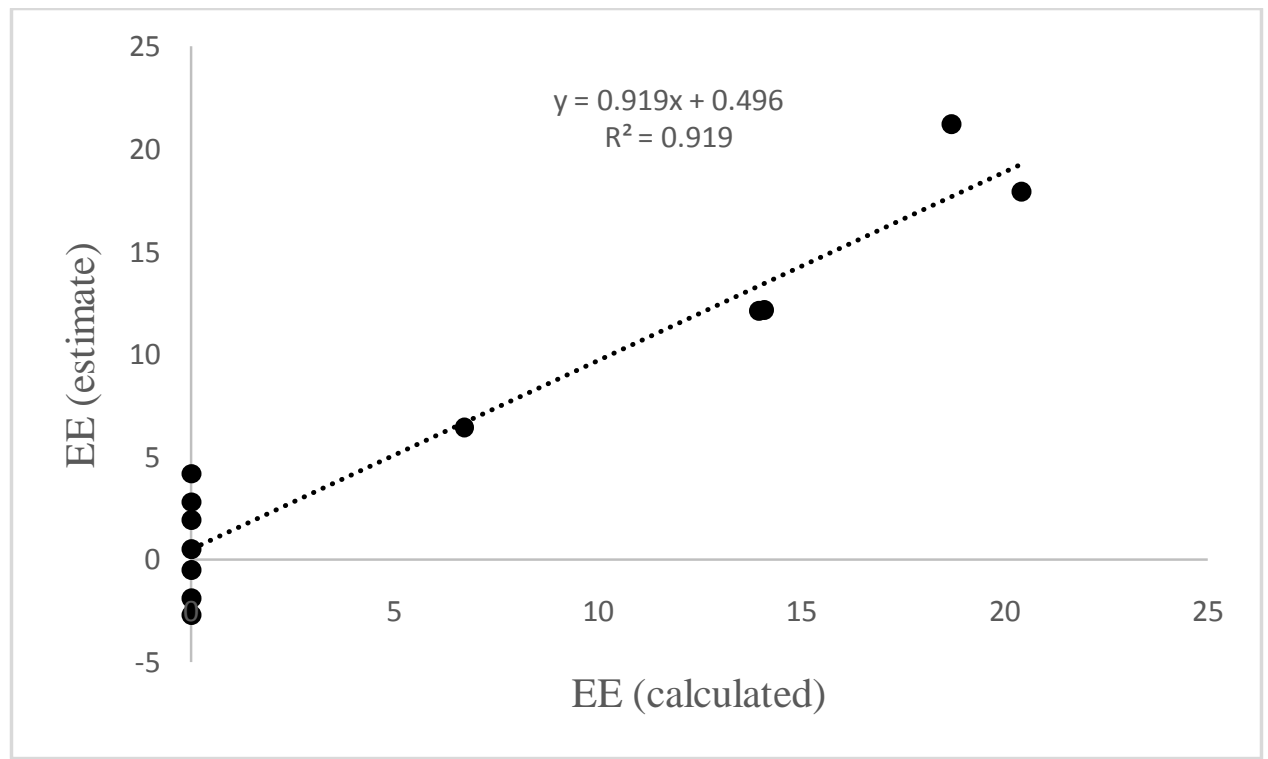

Appear 1 Graph of the EE estimated according to the measured EE

In conclusion, we found a good model, which lead to have a preliminary idea on the influence of the various factors. However, the significant residual values and the lack of adjustment observed, show that the linear model cannot describe the phenomenon correctly and that other significant terms, like quadratic interactions or terms should not be excluded. Consequently, we decided to pass on second model degree of the type: 
$\mathrm{y}=\mathrm{b} 0+\sum \mathrm{bi} \mathrm{xik}+\sum \sum \mathrm{bijxikxjk}+\sum \mathrm{bik} \mathrm{xik} 2+\xi \mathrm{k} \ldots($ Equation 1$)$

The question which arises then, relates to the plan of second degree to use and the choice of the factors which it is necessary to maintain in the study.

Among the many experimental designs of the second degree, we chose the plan of Box Behnken which does not require a great number of tests. It is easy to implement and already described in similar studies (Zhou et al., 2010; Chang et al., 2007).

Concerning the choice of the factors, we are based on the results of the screening plan but also on experimental criteria. One should not lose sight of the fact that the experimental criterion, based on technical and scientific considerations, is always priority compared to the purely statistical criteria (Goupy, 2005). Thus, among the 6 factors introduced at the beginning into the screening plan, the values of two (2) of them were fixed and the four (4) others were use in the Box-Behnken plan:

As we plan to use cheap bioethanol, often hydrated $\left(95^{\circ}\right)$ (Brunschwig et al.. , 2011), for the production of biodiesel, the water content seemed to us an operational factor important to study. Indeed, a minimal quantity of water is necessary to the catalytic activity of lipases; however a too significant quantity of water increases the risk of hydrolysis of the TG or formed esters (Kumari et al.. , 2009), of the barrier effect and/or the aggregation of enzymatic proteins,

- the molar ratio TG:EtOH is essential factor taking into account the inhibiting effect of the strong ethanol concentrations on the catalytic activity of lipases in general, as we could read it in the literatures, it is significant to study the influence of the molar ratio EtOH:TG in order to establish its optimal value ( Mittelbach, 1990; Basri et al., 1997),

- it is significant to determine the suitable load in biocatalyst which makes it possible to maximize the conversion of the TAG into EEHV without limiting the phenomena of mass transfer.

In conclusion, the 4 factors retained for the plan of Box-Behnken are the latex rate, the water activity, the reaction duration and the molar ratio (table 4). Concerning this last factor, although it is given statistically as can influence, it was nevertheless preserved in the study. It is indeed, a parameter generally described like significant by many authors ( Mittelbach, 1990; Basri et al., 1997).

Table 1 Plan of Box-Behnken and resulted them experimental obtained.

\begin{tabular}{|l|l|l|l|l|l|}
\hline EN & aaw & Latex amount $(\%)$ & $\begin{array}{l}\text { Reaction duration } \\
\text { (day) }\end{array}$ & $\begin{array}{l}\text { Molar ratio } \\
\text { (hoil :alcool) }\end{array}$ & $\begin{array}{l}\text { EE } \\
(\%)\end{array}$ \\
\hline 1 & 0.507 & 15 & 4 & $(2,6: 1)$ & 25.286 \\
\hline 2 & 0.507 & 0 & 4 & $(1: 5)$ & 0 \\
\hline 3 & 0.05 & 15 & 4 & $(5: 1)$ & 3.352 \\
\hline 4 & 0.964 & 15 & 1 & $(2,6: 1)$ & 14.095 \\
\hline 5 & 0.05 & 15 & 1 & $(2,6: 1)$ & 6.716 \\
\hline 6 & 0.507 & 0 & 7 & $(2,6: 1)$ & 0 \\
\hline 7 & 0.964 & 15 & 7 & $(2,6: 1)$ & 14.627 \\
\hline 8 & 0.507 & 15 & 7 & $(1: 5)$ & 52.05 \\
\hline 9 & 0.964 & 0 & 4 & $(2,6: 1)$ & 0 \\
\hline 10 & 0.507 & 0 & 1 & $(2,6: 1)$ & 0 \\
\hline 11 & 0.507 & 15 & 7 & $(5: 1)$ & 5.353 \\
\hline 12 & 0.507 & 15 & 4 & $(2,6: 1)$ & 25.28 \\
\hline 13 & 0.05 & 30 & 4 & $(2,6: 1)$ & 1.128 \\
\hline 14 & 0.507 & 30 & 1 & $(2,6: 1)$ & 1.002 \\
\hline 15 & 0.05 & 15 & 7 & $(2,6: 1)$ & 13.975 \\
\hline 16 & 0.507 & 15 & 4 & $(2,6: 1)$ & 25.284 \\
\hline 17 & 0.507 & 0 & 4 & $(5: 1)$ & 0 \\
\hline 18 & 0.507 & 30 & 7 & $(2,6: 1)$ & 10.12 \\
\hline 19 & 0.05 & 0 & 4 & $(2,6: 1)$ & 0 \\
\hline
\end{tabular}




\begin{tabular}{|l|l|l|l|l|l|}
\hline 20 & 0.507 & 30 & 4 & $(5: 1)$ & 1.812 \\
\hline 21 & 0.05 & 15 & 4 & $(1: 5)$ & 0.987 \\
\hline 22 & 0.507 & 15 & 1 & $(1: 5)$ & 10.012 \\
\hline 23 & 0.964 & 15 & 4 & $(5: 1)$ & 3.675 \\
\hline 24 & 0.964 & 15 & 4 & $(1: 5)$ & 15.98 \\
\hline 25 & 0.507 & 15 & 1 & $(5: 1)$ & 3.12 \\
\hline 26 & 0.507 & 30 & 4 & $(1: 5)$ & 40.021 \\
\hline 27 & 0.964 & 30 & 4 & $(2,6: 1)$ & 9.085 \\
\hline
\end{tabular}

The statistical data processing of table 4 with Minitab software, makes it possible to estimate the coefficients of the model (cf. equation 1) (table 5).

Table 2Coefficients of the model for the answer: (Yobs) output in EE obtained.

\begin{tabular}{|l|l|l|}
\hline Term & Coeff & $\mathrm{P}$ \\
\hline Constant & -47.1988 & $0.017^{*}$ \\
\hline Aw & 67.483 & $0.024^{*}$ \\
\hline Latex amont & 2.4744 & $0.007^{* *}$ \\
\hline Reaction duration & 9.4995 & $0.044^{*}$ \\
\hline Molar ratio & 11.4865 & $0.038^{*}$ \\
\hline aw*aw & -51.8018 & $0.012^{*}$ \\
\hline Latex amont * Latex amont & -0.0594 & $0.003^{* *}$ \\
\hline Reaction duration * Reaction duration & -0.5431 & $0.205 \mathrm{NS}$ \\
\hline Molar ratio Molar ratio & -0.7337 & $0.269 \mathrm{NS}$ \\
\hline aw* Latex amont & 0.2902 & $0.645 \mathrm{NS}$ \\
\hline aw* Reaction duration & -1.2267 & $0.697 \mathrm{NS}$ \\
\hline aw* Molar ratio & -3.3438 & $0.401 \mathrm{NS}$ \\
\hline Latex amont* Reaction duration & 0.0507 & $0.599 \mathrm{NS}$ \\
\hline Latex amont *Ratio molaire & -0.2653 & $0.043^{*}$ \\
\hline Reaction duration*Ratio molaire & -1.3821 & $0.036^{*}$ \\
\hline &
\end{tabular}

Through the analysis of table 4 and 5, the principal and quadratic factors have significant effects, contrary in the majority of the interactions between factors. None significance of the interactions between factors shows that the effect of a factor does not depend on the level on the other. In addition, the interaction between the factor rate of latex and molar ratio on the one hand and between the reaction time and the molar ratio on the other hand are significant. Indeed, the latex concentration, the molar ratio between oil and alcohol as well as the time which the reaction would have taken are correlated and determine the ethyl ester yield to obtain.

Table 3 Analyze of variance of the studied experimental answer Yobs = outputs in EEHV.

\begin{tabular}{|c|c|c|c|c|c|}
\hline Source & DL & SC & $\mathrm{MC}$ & $\mathrm{F}$ & $\mathrm{P}$ \\
\hline Regression & 14 & 3673.79 & 262.414 & 3.69 & $0.015^{*}$ \\
\hline Lineair & 4 & 1588.65 & 264.833 & 3.73 & $0.034 *$ \\
\hline Aw (x1) & 1 & 81.66 & 476.91 & 6.71 & $0.024 *$ \\
\hline Latex amont (x2) & 1 & 332.52 & 733.224 & 10.32 & $0,007^{*}$ \\
\hline Reaction duration (x3) & 1 & 311.92 & 358.132 & 5.04 & $0.044 *$ \\
\hline Molar ratio (x4) & 1 & 862.55 & 386.617 & 5.44 & $0.038^{*}$ \\
\hline Square & 4 & 1222.33 & 305.582 & 4.3 & $0.022^{*}$ \\
\hline aw*aw $\left(x 1^{2}\right)$ & 1 & 266.37 & 624.242 & 8.79 & $0.012^{*}$ \\
\hline Latex amont $*$ Latex amont $\left(\mathrm{x}^{2}\right)$ & 1 & 788.1 & 954.119 & 13.43 & $0.003 * *$ \\
\hline Reaction duration $*$ Reaction duration $\left(\mathrm{x} 3^{2}\right)$ & 1 & 72.61 & 127.401 & 1.79 & $0.205^{\mathrm{NS}}$ \\
\hline Molar ratio $*$ Molar ratio $\left(\mathrm{x} 4^{2}\right)$ & 1 & 95.25 & 95.248 & 1.34 & $0.269^{\mathrm{NS}}$ \\
\hline Interaction & 6 & 862.82 & 143.803 & 2.02 & $0.141^{\mathrm{NS}}$ \\
\hline
\end{tabular}




\begin{tabular}{|c|c|c|c|c|c|}
\hline aw* Latex amont $(x 1 * x 2)$ & 1 & 15.83 & 15.828 & 0.22 & $0.645^{\mathrm{NS}}$ \\
\hline aw* Reaction durarion $(x 1 * x 3)$ & 1 & 11.31 & 11.313 & 0.16 & $0.697^{\mathrm{NS}}$ \\
\hline aw*Ratio molaire $(\mathrm{x} 1 * \mathrm{x} 4)$ & 1 & 53.8 & 53.802 & 0.76 & $0.401^{\mathrm{NS}}$ \\
\hline Latex amont $*$ Reaction duration $(\mathrm{x} 2 * \mathrm{x} 3)$ & 1 & 20.78 & 20.784 & 0.29 & $0.599^{\mathrm{NS}}$ \\
\hline Latex amont $*$ Ratio molar $(\mathrm{x} 2 * \mathrm{x} 4)$ & 1 & 364.98 & 364982 & 5.14 & $0.043^{*}$ \\
\hline Reaction duration *Ratio molar $(\mathrm{x} 3 * \mathrm{x} 4)$ & 1 & 396.11 & 396.11 & 5.57 & $0.036^{*}$ \\
\hline residual error & 12 & 852.65 & 71.054 & & \\
\hline Inadéquacyajustment & 10 & 852.65 & 85.265 & 9135518.44 & 0 \\
\hline Pur error & 2 & 0 & 0 & & \\
\hline Total & 26 & 4526.44 & & & \\
\hline
\end{tabular}

By analysis of table 5 the equation of prediction of transeterification gives: Yped $=-47.1988+67.483 \mathrm{X} 1+2.4744 \mathrm{X} 2+9.499 \mathrm{X} 3+11.4865 \mathrm{X} 4-51.8018 \mathrm{X} 12-0.0594 \mathrm{X} 22-0.2653 \mathrm{X} 2 \mathrm{X} 4-$ $1.3821 \mathrm{X} 3 \mathrm{X} 4$

Starting from the experimental results of experimental design and the equation of prediction obtained, curves of isoréponses can be generated by software STATISTICA ${ }^{\circledR}$. The exploitation of these curves makes it possible to visualize and determine the optimum conditions for cross esterification valid in the experimental field. By fixing the level of one of the four factors at its value in the center of the experimental field, it is then possible to follow the evolution of the parameters two to two.

\section{Response surface curves of the statistical analysis of the factors influencing transesterification using F.trichopodalate:-.}

Analysis of the results of the response surface curves, show that the EE yeald is strongly influenced as well by the activity of the water of latexes as the lipase rate in the reactional medium (figure a).

Indeed, according to work of GrajekandGervais (1987), of Lee and Kim (1995), of Bell et al. (1997) and of Ducretet al. (1998), the enzymatic activity is strongly influenced by the activity of the water of the biocatalysts. In the reactions of hydrolysis for example, water is used as active reagent and a medium of diffusion to put the enzyme in contact with the substrate. Thus, the reduction of the availability of water often induced a reduction in quickly of the reaction (Grajek and Gervais, 1987). In addition, during a reaction of transformation of a fat content, a strong quantity of enzyme can contribute to poor yield of the finished product. The low fat content to be transformed compared to the enzyme can involve the encapsulation of the biocatalysts from where a bad dispersion of the latter in the reactional medium (Tonova and Lazarova, 2008; Santos et al., 2013).

The yield of EE is very low for very weak water activity in the latex and the concentration in biocatalyst as for very strong water activity in the latex and the concentration in biocatalyst. A high yield of EE, about $20 \%$ is obtained for a water activity around 0.507 and latex rate from 15 to $20 \%$ compared to the quantity of oil. The EE yield is however corrected and re-examined with the rise for a rate of latex average of $20 \%$ compared to the quantity of oil when the water activity is very weak $(0.05)$ or very high $(0,984)$. The corrective effect of the yield is also for molar ratios high at the time the latex rate is maintained around 20\% (figure E)

On the figures (b) and (d) we note that the duration has a positive impact on the output in EE. More the hard reaction, more the oyield is high. However, it is possible to observe that the negative effect of the high or the weak activity ratio of water on the yield of transesterification is dominating.

For small molar ratios TAG:EtOH, the yield of EE is high no matter what would be the content of water activity in latex (figure c). This report could be explained by the fact that the ethanol used within the framework of this work is exclusively of absolute ethanol. The surplus of water of latexes could be dissimulated in ethanol.

According to the figure $\mathrm{f}$, when the molar ratio is high, the duration of the reaction does not have a significant effect on the EE yield. 
Figure 3:-Iso-response curve of the yield of EE formed using latex of Ftrichopoda.

$\mathrm{a}^{\circ}$ ) Response surface of the effect of the latex rate and the aw of latex on the yield of EE.

$\left.b^{\circ}\right)$ Response surface of the effect of and the aw reaction time of latex on the yield of EE.

$\left.c^{\circ}\right)$ Response surface of the effect of the molar ratio and the aw of latex on the yield of EE.

$\mathrm{d}^{\circ}$ ) Response surface of the effect of latex rate and the reaction time on the yield of EE.

$\left.\mathrm{e}^{\circ}\right)$ Response surface of the effect of the molar ratio and the latex rate on the yield of EE.

$\mathrm{f}^{\circ}$ ) Response surface of the effect of the reaction time and molar ratio on the yield of EE.
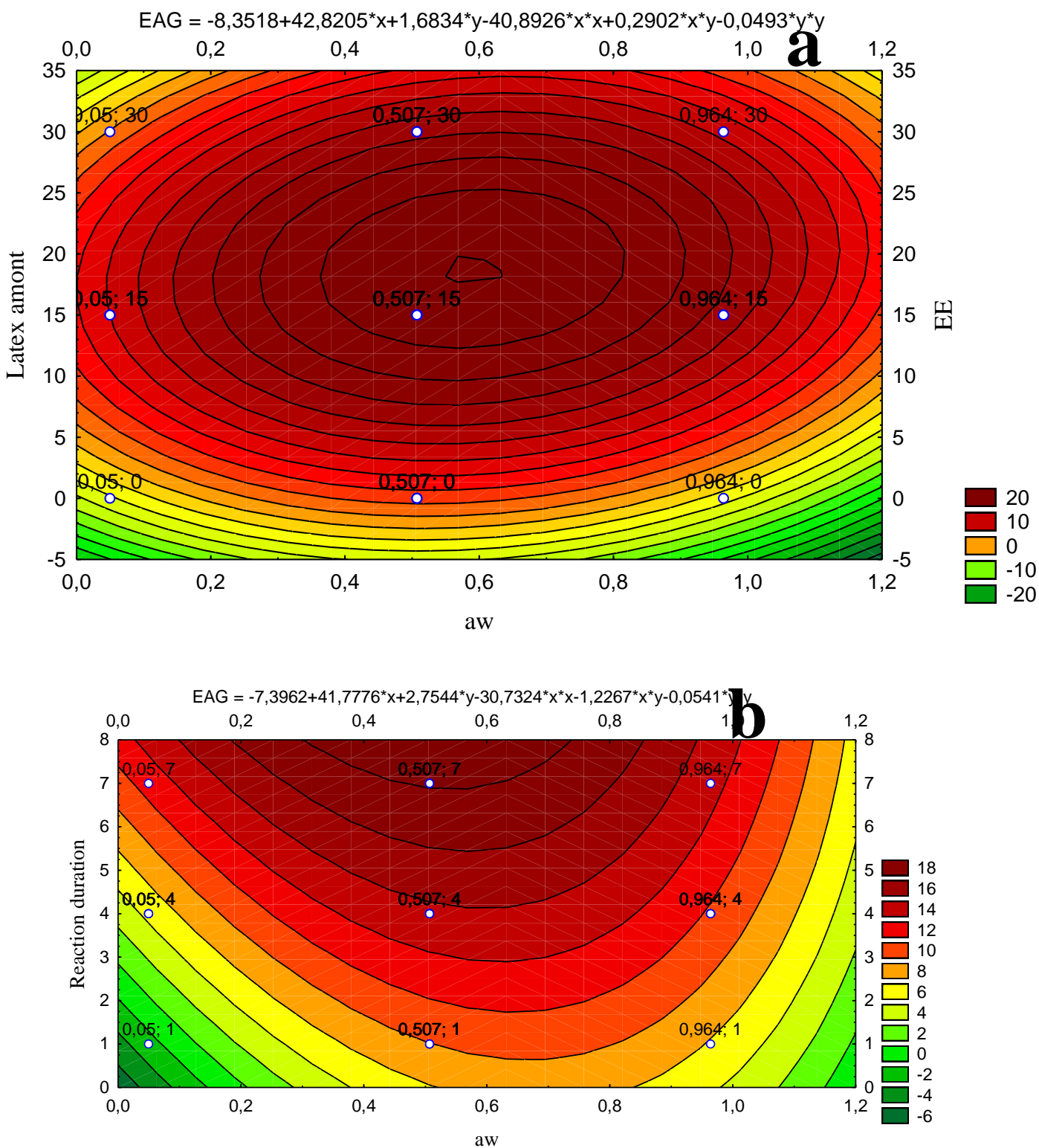

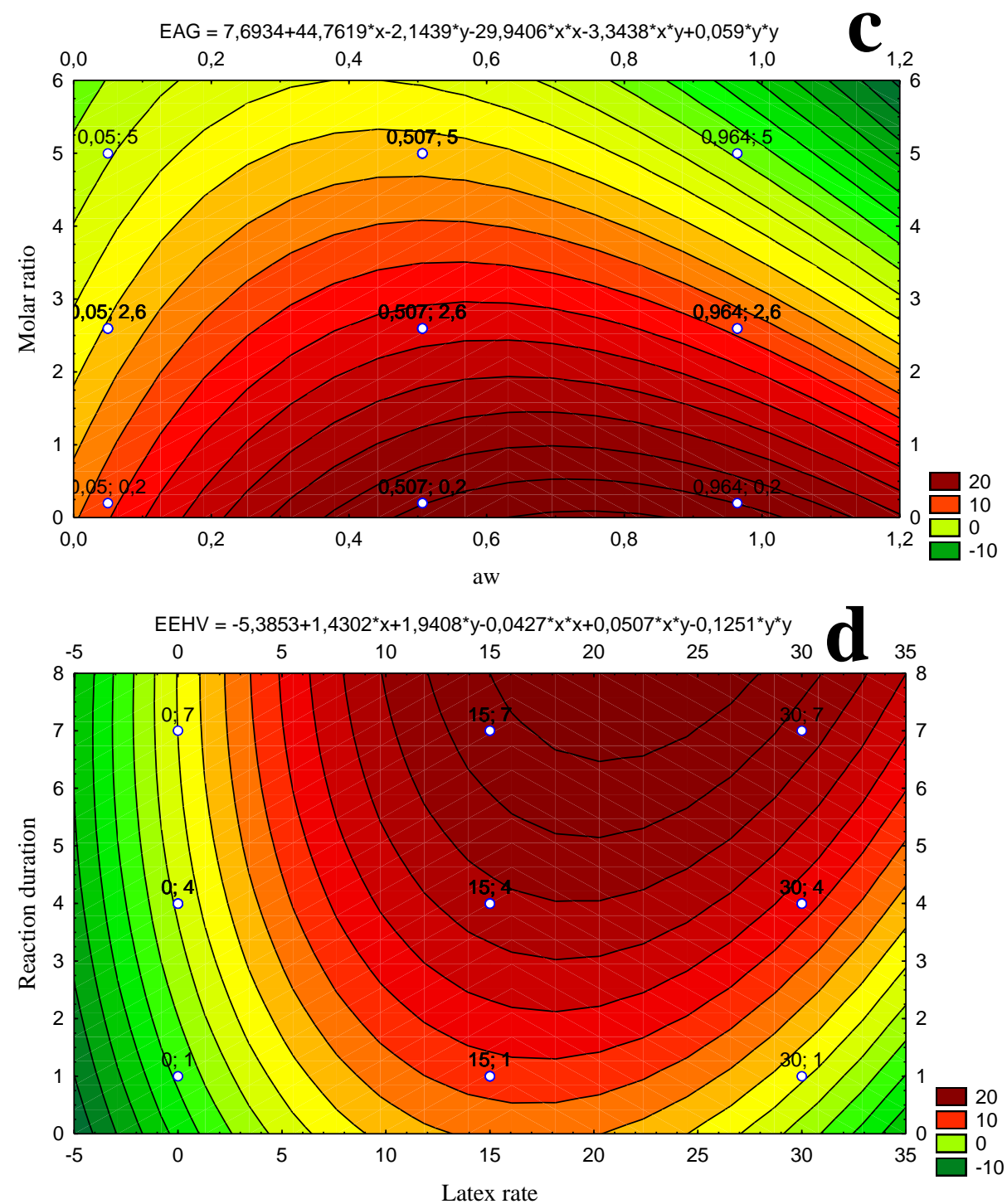

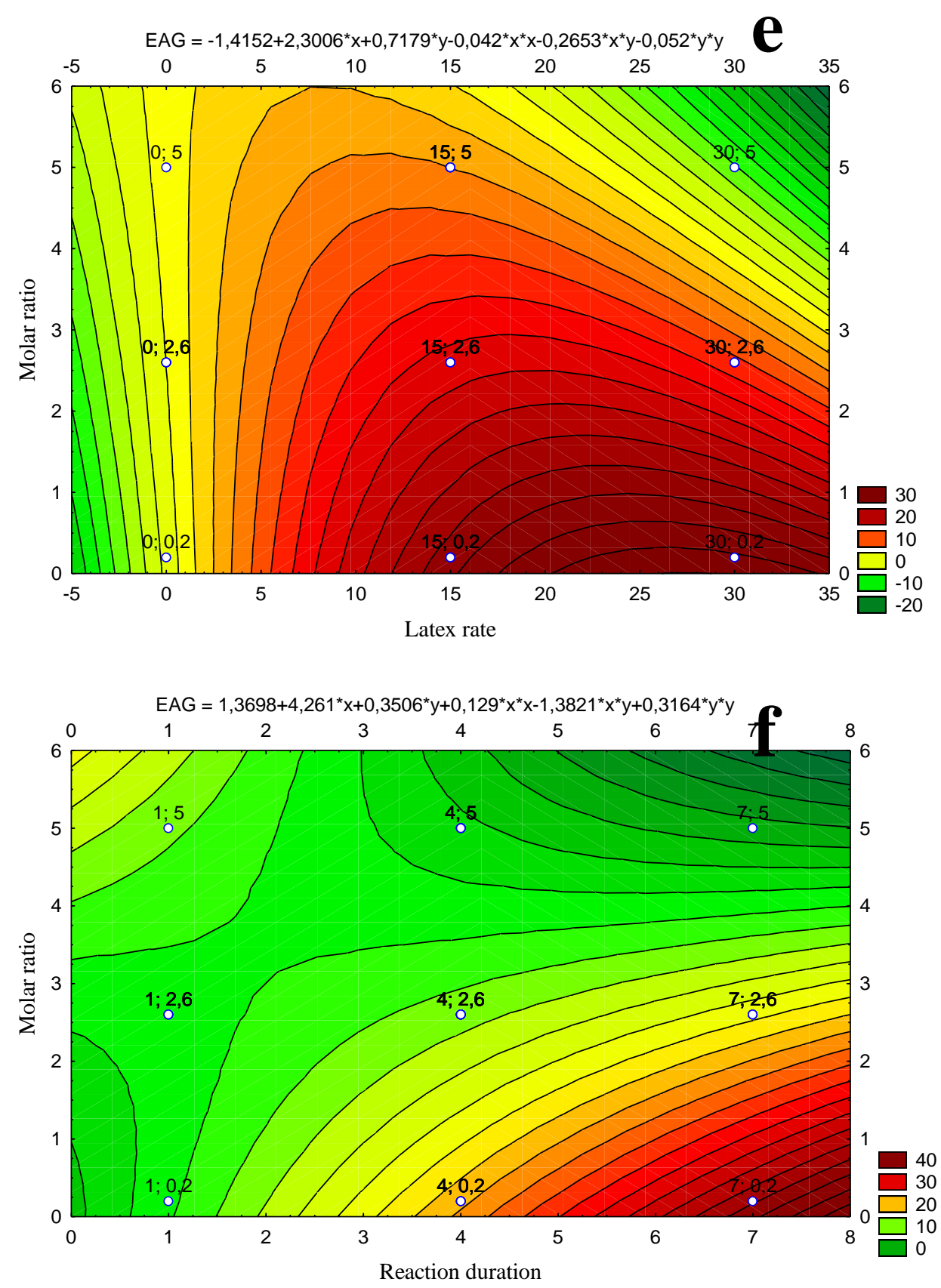

\section{Optimization by the desirability function:-}

The precise value of the theoretical optimum, corresponding to the maximum value in EE, as well as the values of the factors making it possible to reach it were given using the function "desirability" of software MINOTAB (figure 4). 


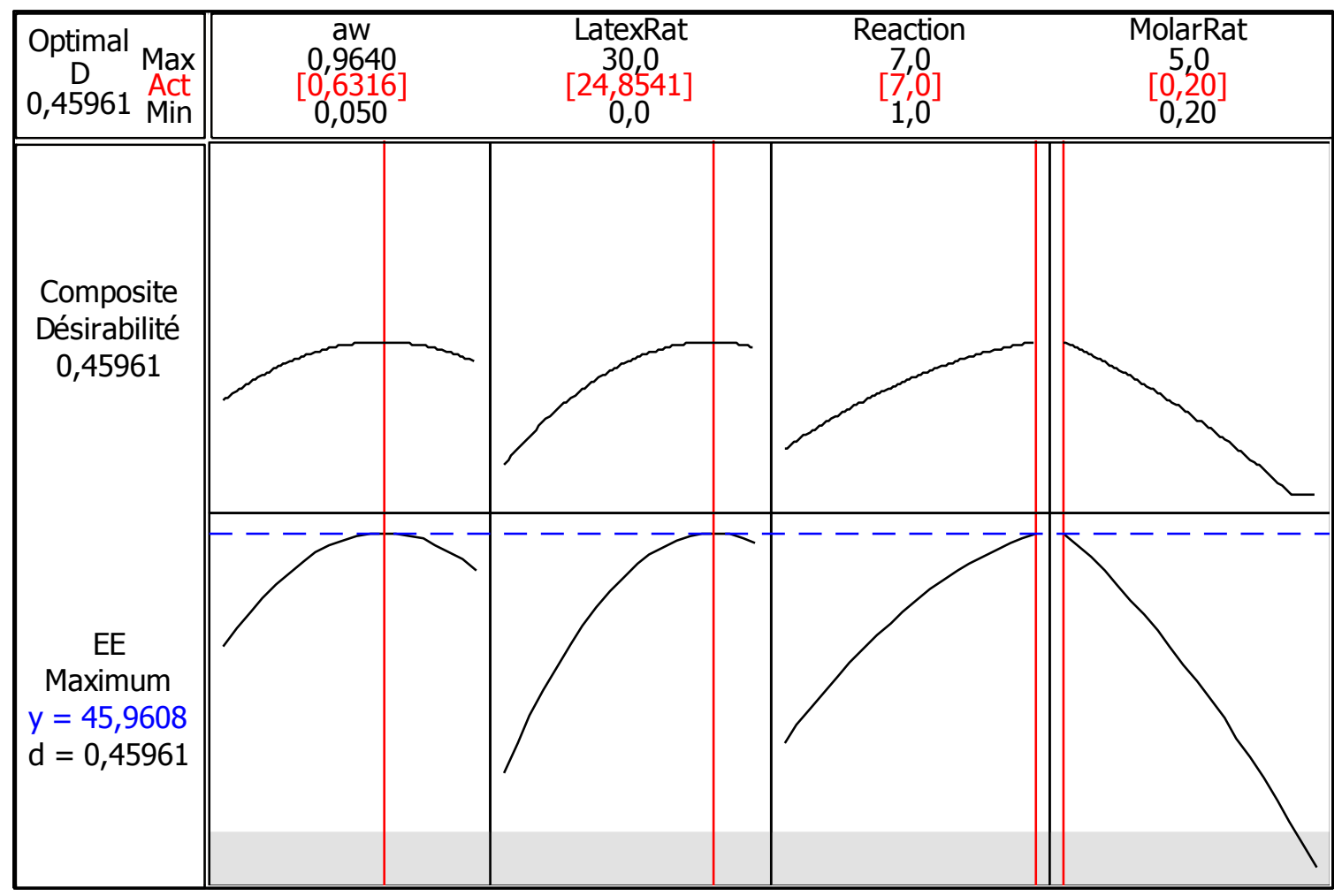

Figure 4:- Optimization by the "desirability" function.

As figure 4 shows it, the value of the coefficient of maximum EE estimated by the model $(45,96 \%)$ corresponds to the values of the levels according to:

aw $=0,63$

Latex rate $=24,85 \%$

Reaction time 7 days

Molar ratio (1: 5)

It is clear that the experimental conditions of transesterification have an action on the operation of protein contained in latex of $F$. trichopoda. Indeed, the molar ratio, the catalyst load and the activity of water in latexes are the factors which make it possible to control the oyield of transesterification of vegetable oil with ethanol using latex of F.trichopoda. In addition to the determination of the principal effects of the various factors, the methodology of the experimental designs, made it possible to determine the various studied interactions between the factors. Table 5 highlights that the interaction enters the molar ratio and the catalyst load has a negative and considerable impact on the oyield of transesterification. This same report was by Mounguengui (2016) on the extracts of germinated Jatropha and Moringa when it used them as biocatalyst in reactions of ctransesterification for the production of biodiesel. In the same way, this table (table 5) allows us noted that the interaction enters the molar ratio and the duration of the reaction has a negative and considerable impact on the oyield of transesterification. However, to refine the optimization of the oyield of transesterification, the molar ratio and the latex rate should not evolve/move in the same direction. The increase in the latex rate must be accompanied by the reduction by the molar ratio.

In addition, the yield of transesterification at the end of the reaction turn around $46 \%$. For a total reaction the yield of EE should reach values close to $100 \%$. Two assumptions can make it possible to understand which are the factors which can be responsible for these poor yield:

a progressive inhibition of the extracts by the ethanol which did not react, or a competitive inhibition by one or products of transesterification. 
Transesterification complete of the palm oil with ethanol using latex of Ftrichopoda:-

Results of the function of desirability permit us reaching a yield of EE close to $46 \%$. The tests of transesterification carried out did not make it possible to reach the complete conversion of the refine palm oil using latex of F.trichopodaunder the conditions of reaction implemented. A complete conversion or at least near to $100 \%$ is the ideal one that we propose to reach.

To overcome this difficulty, we planned the conversion of the palm oil into two successive reactions of transesterification by renewed latex in the reactional medium. Indeed, we will use as substrate in the second stage the oil partially trans-esterified obtained after the initial reaction.

While using an oil partially trans-esterified as substrate with new catalyst, the experiment suits us to enable us to check inter alia if there is a specificity of the lipases contained in latex of F.trichopoda screw - with - screw of the substrate, certain functions hydrolysable or certain fatty acids, which is responsible for the limitation of the conversion of the TG into EE.

\section{Implementation of two successive reactions for transesterification of refine palm oil with ethanol using latex of F. trichopoda:-}

The reactional medium obtained after an initial reaction of ethanolic transesterification on the palm oil according to conditions of the function of desirability is overallcentrifuged at $4000 \mathrm{rpm}$ during $20 \mathrm{~min}$. oil is separate of the base made up mainly of latex. Recovered oil is dried with the drying oven with $45^{\circ} \mathrm{C}$ during 30 min so eliminated the residual ethanol from the reactional medium. After cooling with the dedicator, the filtrate is then used like substrate for a new reaction of transesterification always according to conditions of the function of desirability.

The analysis of the composition of the various reactional mediums by TLC showed that the conversion of the TAG into EE by latex of F.trichopoda is not complette(Figure 5).

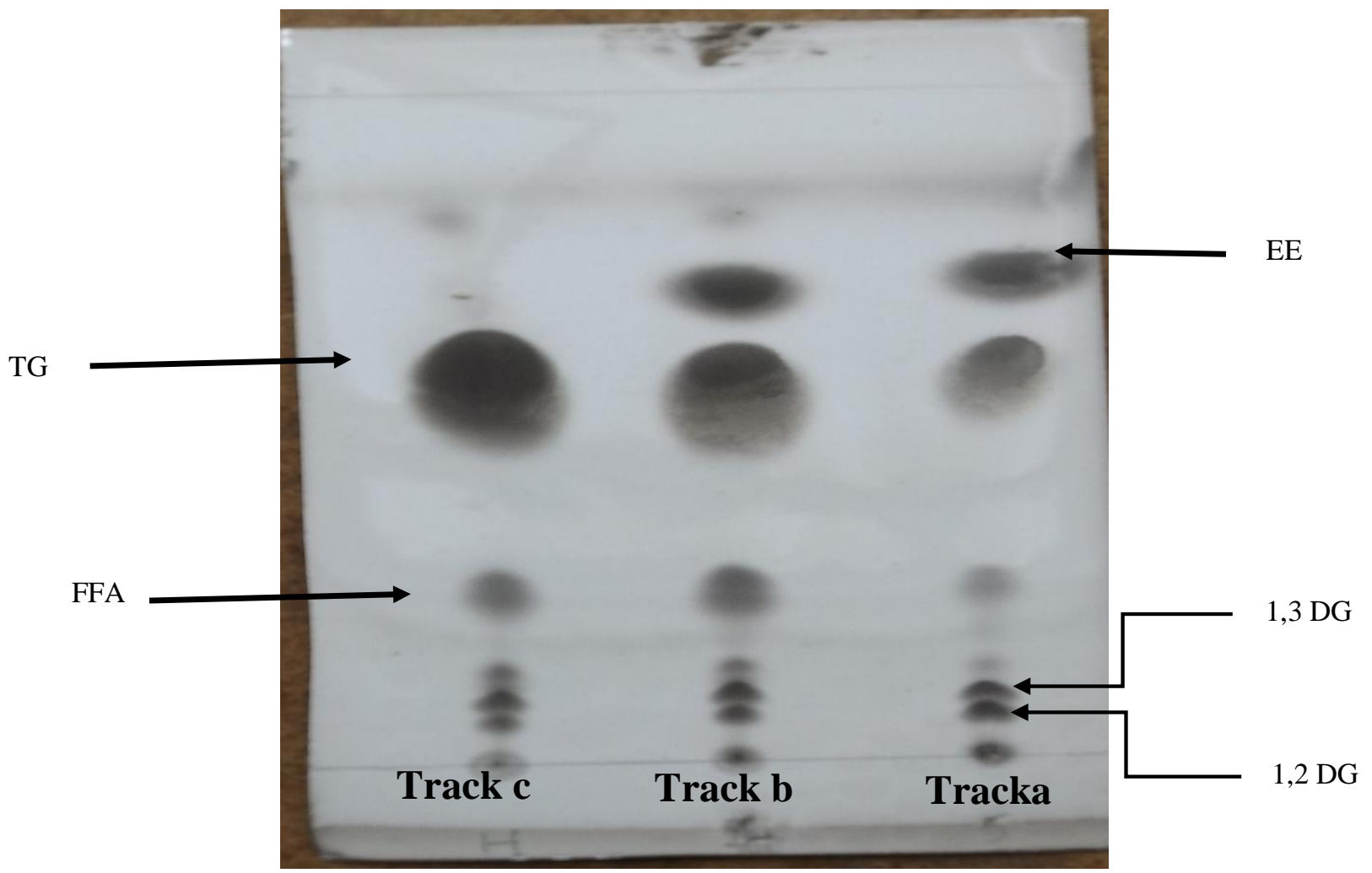

Figure 5:-TLC Analyze of the composition of the reactional mediums after ethanolic transesterification of palm oil catalyzed by latex of $F$. trichopoda 
At the end of the reactions the medium seems to contain a small quantity of FFA, but contains he DG and MG, in proportional quantity with concealment initially present in the medium before the second reaction of transesterification (Figure 5, track a and b).

The results of GC analysis (Table 6) of the composition of the reactional medium reveals that $49.39 \%$ of the TG were transformed into EE and a small quantity of FFA (6.17\%) visible in TLC (Figure 5 tracks a). We note in addition a supplementary formation $\mathrm{MG}$ and $\mathrm{DG}$ compared to the first phase of reaction (Table 6). The implementation of two successive reactions of transesterification surely allowed a supplementary conversion of TG of the palm oil into EE using latex of F. truchopodabut also generated the formation of the secondary elements. The formed secondary elements would be responsible for the limitation of the conversion of the TG into EE. Another assumption would be that lipase contained in the latex of $F$. trichopodais not sufficiently effective under the selected operating conditions to continue the transesterification of the TG of the palm oil.

Table 4 Composition of the refine palm oil and the palm oils after ethanolic transesterification catalyzed by latex of F.trichopoda

\begin{tabular}{|l|l|l|l|l|l|}
\hline \multicolumn{7}{|c|}{ constituents\% } & TG & EE \\
\hline Substratum & MG & DG & FFA & TG & 0 \\
\hline Palm oil & 4,247 & 11,058 & 11,099 & 73,596 & 44,5 \\
\hline Phase1 & 4,144 & 8,618 & 11,752 & 30,986 & 51,75 \\
\hline Phase2 & 7,072 & 10,8 & 6,17 & 24,208 & 5 \\
\hline
\end{tabular}

In addition, the latex of F.trichopodais performant than the vegetable extracts of germinatedMoringa but less than that of germinated Jatropha. In fact, contrary to the extracts of germinated Jatropha, the analysis of the composition of the reactional medium were transesterification was carried out with the vegetable extracts of germinated Moringa reveals a conversion from only $48.5 \%$ of the TG into a mixture EE and FFA. The reactional medium amongst other things contains $25.2 \%$ of residual TG, $13.8 \%$ DG and $12.5 \%$ of MG (Mounguengui et al.. , 2016)

The latex of F.trichopoda represents in the same way a powerful catalyst for the derivation of the ethyl ester TG.

\section{Kinetic of transesterification using latexes:-}

In this work, the synthesis of EE using latex of F.trichopoda was done on a small scale with quantity of palm oil of $2 \mathrm{~g}$ to $4 \mathrm{~g}$. We considered it interesting to check its feasibility on a large scale (500g of oil) to allow future extrapolations. Reaction of transesterification at summer implemented under the optimal conditions described by the function of desirability. In order to following the synthesis of $\mathrm{EE}$, the composition of the reactional medium was analyzed (Figure 6). Samples of the medium were taken all the $24 \mathrm{H}$ then analyzed by GC. The product of the reaction to summer characterized in order to determine certain physico-chemical properties of the biodiesel obtained. 


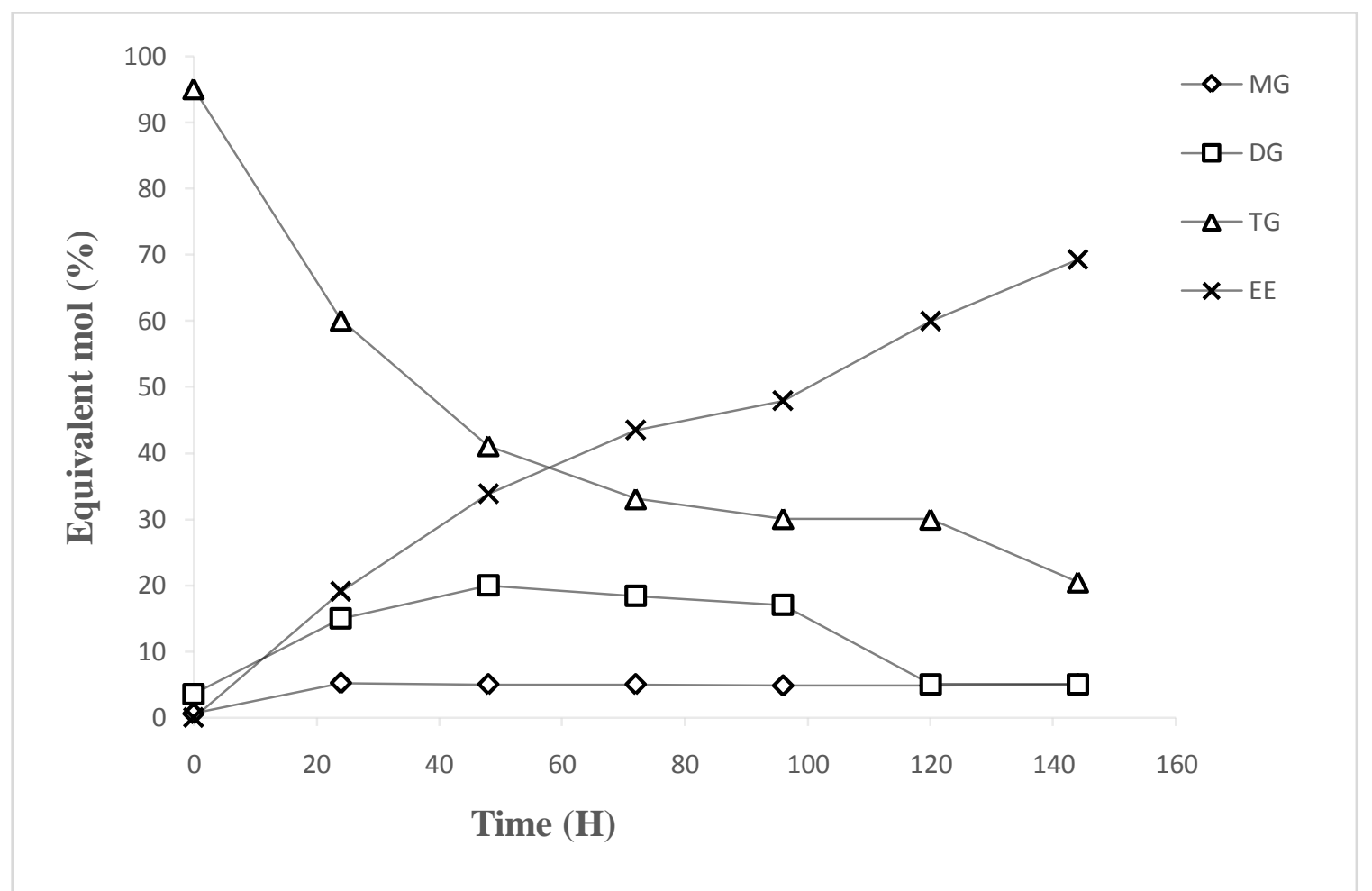

Figure 6:- Curves of evolution of the EE, the TG and the intermediate compounds (MG, DG) during the transesterification of the palm oil catalyzed by latex of F. trichopoda.

By the analysis of this figure (Figure 6) the number of moles of TG falls quickly during 48 first hours. This phenomenon shows well that the TG are the preferential substrate of the lipase of latex of F.trichopoda. Among the $95.12 \%$ of starting TG, $48.8 \%$ converted into EE after $48 \mathrm{H}$ with the formation of the intermediaries of reaction DG $(17,12 \%)$ and MG $(7,3 \%)$. At the end of $72 \mathrm{H}$, the rate of EE does not exceed any more the limit of $52.7 \%$. The reactional medium is however overall centrifuged then oil is re-used for new a reaction. Thus, the yield in EE is $58,12 \%$.

\section{Recycling of latex in transesterification reaction:-}

In order to check the possibility of recycle latexes after a cycle of use, three samples of approximately $2 \mathrm{~g}$ of latex were put in reaction initially in the presence of $10 \mathrm{~g}$ of oil $(20 \% \mathrm{~m} / \mathrm{m})$ and ethanol $2.685 \mathrm{~g}$ corresponding a molar ratio TAG:EtOH ( 1:5) has throughout one 24 hour to $37^{\circ} \mathrm{C}$ before being washed, each with hexane.

After the reaction of transesterification, the reactional medium is centrifuged overall at $4000 \mathrm{rpm}$ during 20 minutes. Oil is withdrawn from the medium and replaced by $10 \mathrm{~mL}$ of hexane. The mixture again is centrifuged and get rid of the supernatant. Washing is taken again second once for assured that the latex gets rid of lipid part then dried with the free air during one night.

The latexes were reused for the transesterification of $20 \mathrm{~g}$ oil with $2.685 \mathrm{~g}$ of ethanol corresponding to a molar ratio TAG:EtOH with (1:5) during $24 \mathrm{~h}$ at $37^{\circ} \mathrm{C}$ washing was carried out to make it possible to eliminate glycerol possibly adsorbed by latex. In this manner, the activity of lipase can be theoretically found what makes possible its reuse.

The results of analysis TLC after $24 \mathrm{H}$ of reaction revealed that after second Cycle of use, any esters ethyl is not formed during tests of transesterification catalyzed by latexes of F.trichopoda washed with hexane (Figure 7).

The absence of EE to the second cycle would be according to us due to the mechanical loss of lipases during the process of washing, or the successive cycle of transesterification. Within sight of the results obtained, with the modes of recovery and washing of the latexes which we tested, it appears that the recycling of latexes of $F$. 
trichopoda as biocatalyst after two cycle catalytic of transesterification is not for the moment possible. Work to allow the recycle latexes is to be continued.

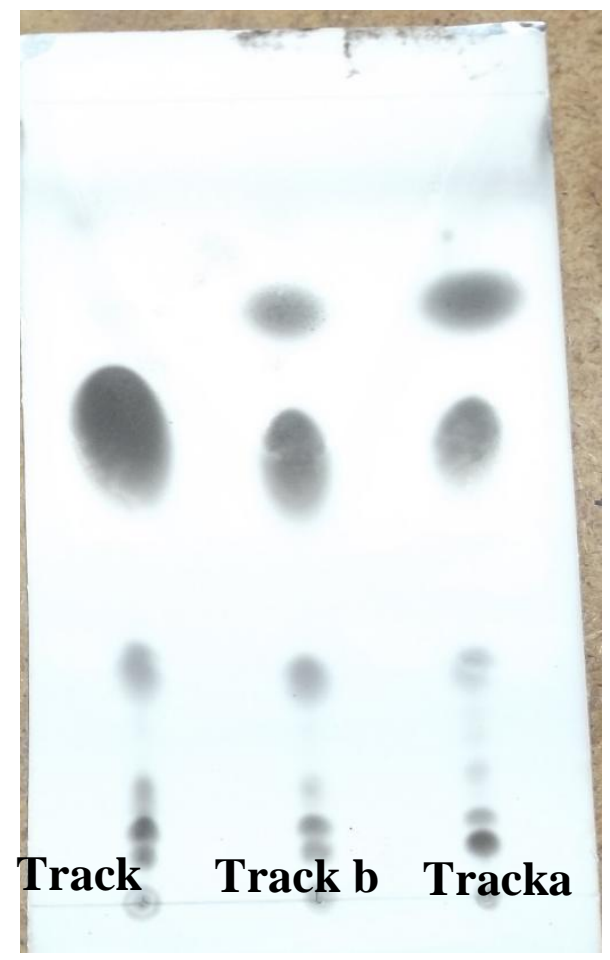

Track a: initial reaction

Figure 7:- Recycling of Ftrichopoda latex in transesterification reaction

Track b: first cycle

Track C: second cycle

\section{Conclusion:-}

This study led to the identification of biomass (latex) from West Africa that are potential sources of active lipases for the transesterification of vegetable oils. The catalytic activity of the enzymes contained in the crud latex of $F$. trichopoda was two-fold greater than that of over seed extracts. However, work to allow the recycle latexes is to be continued.

\section{Acknowledgements:-}

This publication was prepared with the assistance of PRONOVABIO. The African Union and the European Union were gratefully acknowledged.

\section{References:-}

1. Akoh C.C., Chang S.W, Lee G.C, Shaw J.F. (2007): Enzymatic approach to biodiesel production. J. Agric. Food Chem. 55:8995-9005.

2. Basri, M., Heng, A. \&Razak, C.(1997):Alcoholysis of palm oil mid-fraction by lipase from rhizopusrhizopodiformis. J Am Oil ChemSoc 113-6

3. Bell G., Janssen A.E. M, Halling P. J. (1997):Water activity fails to predict critical hydration level for enzyme activity in polar organic solvents: Interconversion of water concentrations and activities. Enzyme and Microbial Technology. Volume 20, Issue 6, 1 471-477.

4. Brunschwig C, Moussavou W, Blin J (2011): Use of bioethanol for biodiesel production. Progress in Energy and Combustion Science; 38:283e301.

5. Caro Y, Villeneuve P, Pina M, Reynes M, Graille J (2000): Investigation of crude latex from various Carica papaya varieties for lipid bioconversions. J Am Oil ChemSoc 77:891-901. 
6. Cheng Y.C., Tsai S.W. (2004): Enantioselective esterification of (RS)-2-(4- chlorophenoxy) propionic acid via Carica papaya lipase in organic solvents. TetrahedAsymmet 15:2917-20.

7. Ducret A., Trani M., LortieR.(1998): Lipase-catalyzed enantioselective esterification of ibuprofen in organic solvents under controlled water activity. Enzyme and Microbial Technology. Volume 22, Issue 4, 212-216.

8. Grajek W., Gervais P. (1987): Influence of water activity on the enzyme biosynthesis and enzyme activities produced by Trichoderma viride TS in solid-state fermentation. Enzyme and Microbial Technology. Volume 9, Issue 11, 658-662.

9. Jeana S., Macalood H.J., Vicente R.D., Boniao J.G., Gorospe E.C.Roa (2013): Chemical Analysis of Carica papaya L. Crude Latex. Am J Plant Sci4:1941-1948.

10. Lee S. B., Kim K.-J.(1995): Effect of water activity on enzyme hydration and enzyme reaction rate in organic solvents. Journal of Fermentation and Bioengineering. Volume 79, Issue 5, 473-478.

11. Mazou M, Djossou AJ, Tchobo FP, Villeneuve P, Soumanou MM (2016): Plant latex lipases as a biocatalyst for biodiesel production.Afr. J. Biotechnol. 15(28):1487-1502.

12. Mounguengui R.W.M., Brunschwig C., Baréa B., Villeneuve P., Blin J. (2016):Assessing the enzyme activity of different plant extracts of biomasses from sub- saharanafrica for ethyl biodiesel production. Energy Fuels 30(3), 2356-2364.

13. Nitsawang S, Kaulb RH, Kanasawud P (2006): Purification of Papain from Carica papaya Latex: Aqueous Two- Phase Extraction versus Two-Step Salt Precipitation. Enzyme MicrobTechnol 39:1103-1107.

14. Robles-Medina A, Gonzalez-Moreno PA, Esteban-Cerdan L, Molina-Grima E. (2009):Biocatalysis: towards ever greener biodiesel production. BiotechnolAdv;27:198-408.

15. Santos KC, Cassimiro DMJ, Avelar MHM, Hirata DB, de Castro HF, Fernández-Lafuente R, Mendes AA.(2013): Characterization of the catalytic properties of lipases from plant seeds for the production of concentrated fatty acids from different vegetable oils. Ind Crops Prod 49, 462-470.

16. Soumanou MM, Djenontin ST, Tchobo FP, Sohounhloue DC, \&Bornscheuer UT (2012): Lipase-catalysed biodiesel production from Jatropha curcas oil. Lipid Technology, 24(7):158-160.

17. Tonova K., Lazarova Z. (2008):Reversed micelle solvents as tools of enzyme purification and enzymecatalyzed conversion. Biotechnology Advances Volume 26, (6) 516-532.

18. Villeneuve $\mathbf{P}$ (2003): Plant lipases and their applications in oils and fats modification. Eur J Lipid SciTechnol105:308-317.

19. Wang Y,Ou SY, Liu PZ, Zhang ZS (2007): Preparation of biodiesel from waste cooking oil via two-step catalyzed process. Energ. Convers. Manage. 48: 184-188. 